\title{
Prediction of additional lymph node involvement in breast cancer patients with positive sentinel lymph nodes
}

\author{
K. POHLODEK ${ }^{1, \star}$, S. BOZIKOVA ${ }^{1}$, I. MECIAROVA ${ }^{2}$, V. MUCHA ${ }^{3}$, M. BARTOVA ${ }^{1}$, F. ONDRIAS ${ }^{2}$
}

${ }^{1}$ 2nd Department of Obsterics and Gynaecology, Medical faculty, Comenius University of Bratislava, Slovakia, Bratislava, Slovakia (Slovak Republic); ${ }^{2}$ Alpha medical patológia, s.r.o., Bratislava, Slovak republic, Slovakia; ${ }^{3}$ Institute of Virology, Slovak Academy of Sciences, Bratislava, Slovak republic, Slovakia

*Correspondence: kpohlodek@gmail.com

Received September 22, 2015 / Accepted November 6, 2015

\begin{abstract}
Axillary lymph node dissection (ALND) has traditionally been the principal method for evaluating axillary lymph node status in breast cancer patients. In the past decades sentinel lymph nodes biopsy after lymphatic mapping has been used to stage the disease. The majority of sentinel lymph nodes (SLN) positive patients do not have additional metastases in nonsentinel nodes (non-SLN) after additional ALND. These patients are exposed to the morbidity of ALND without any benefit from additional axillary clearence. In the present study we would like to asses the criteria for selecting those patients, who have high risk for non-SLN metastases in the axilla in cases of positive SLN. In this retrospective analysis, clinical and pathologic data from 163 patients who underwent SLN biopsy followed by ALND were collected. Following clinical and pathological characteristics were analyzed to predict the likehood of non-SLN metastases: age, staging, histologic type and grading of the tumors, hormonal receptor status, HER-2 receptor status and Ki-67 protein, angioinvasion, metastases in SLN and nonSLN. Relative frequencies of individual characteristics between sample groups were statistically tested by Chi-square test at significance level $\mathrm{p}=0.5$, when sample sizes in groups were small $(\leq 5)$ by Fisher's exact test. Metastasis in SLN were present in $67(41 \%)$ of patients, 48 patients $(29,4 \%)$ had metastasis also in non-SLN. The ratio between non-SLN positive / non-SLN negative lymph nodes in patients with positive SLN increases with the stage of the disease, the difference between values for the pT1c and pT2 stadium was statistically significant $(\mathrm{p}=0.0296)$. The same applies to grading, but the differences were not significant $(\mathrm{p}>0.05)$. We could not find significant differences for angioinvasion of the tumor, probably for small number of patients with angioinvasion $(\mathrm{p}>0.05)$.

Only the stage of the tumor was shown to be significant in predicting the metastasis in non-SLN in our group of breast cancer patients with positive SLN Nearly $80 \%$ of the patients of 70 years and older displayed no benefit from axillary staging, because of negative SLN as well as non-SLN, although thanks to the small sample size this was not a statistically significant result. Furthermore, current recommendations for axillary staging in breast cancer patients are discussed.
\end{abstract}

Key words: breast cancer, surgery, sentinel lymph node biopsy, axillary dissection

Axillary lymph node status is the most important prognostic factor in patients with breast cancer [1]. Axillary lymph node dissection (ALND) has traditionally been the principal method for evaluating axillary lymph node status. In recent years, ALND has been considered as a staging procedure offering prognostic information, but contributing little to the chances of breast cancer cure. In the last three decades evaluation of axillary sentinel lymph nodes (SLN) after lymphatic mapping is used to stage breast cancer patients. Many studies have appeared validating the use of sentinel lymph node biopsy (SLNB) as an accurate means of detecting metastatic disease in the axillary lymph nodes in patients with breast cancer [2-10]. SLNB was established as an accurate method of determining axillary node status [8-11]. It also provides prognostic information, but has lower morbidity than conventional ALND [6,7]. ALND is still recommended for patients with metastatic SLN, in order to refine the prognosis, to maintain local control of the axilla, and for a potential therapeutic benefit. The majority of SLN positive breast cancer patients have not additional metastases in non-sentinel lymph nodes (non-SLN) after additional ALND [9-11]. These patients experience the morbidity of 


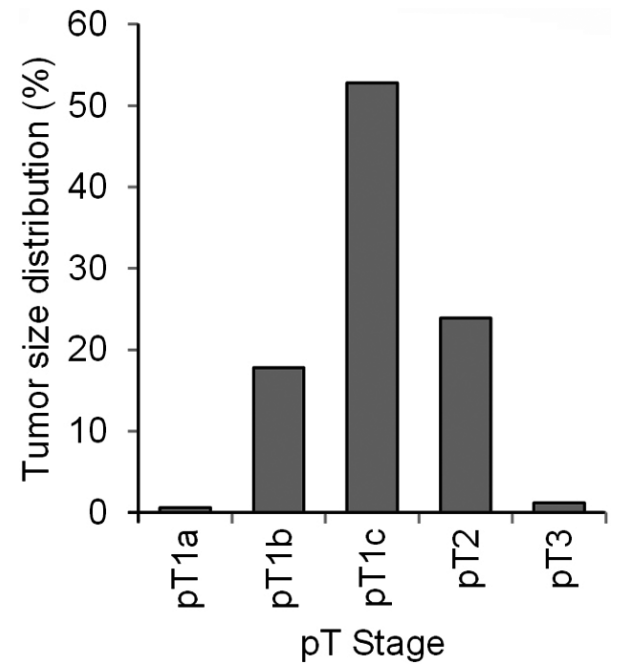

Figure 1.Tumor size distribution (pT-staging)

ALND without any benefit from additional axillary clearence. In the present study we would like to asses the criteria for selecting those patients, who have high risk for non-SLN metastases in the axilla in cases of positive SLN.

\section{Patients and methods}

In this study, clinical and pathologic data from 163 patients who underwent surgical treatment of breast cancer with SLNB followed by ALND at the $2^{\text {nd }}$ Department of OB/GYN, University Hospital of Bratislava, Slovakia between 2001 2013 were collected and analysed. Mostly patients from the initial period, in which all SLNB were followed by ALND for estimation of detection rate, false negativity, specificity of the method, etc, were selected. Another group are patients with positive SLN, all of them received ALND. Patients with nega-

Table 1. Histopathologic types of tumors

\begin{tabular}{lcc}
\hline Type of the tumor & Frequency & Percent \\
\hline DCIS & 3 & 1.8 \\
ductal-lobular & 2 & 1.2 \\
ductal, NOS & 122 & 74.8 \\
ductal+lobular & 4 & 2.5 \\
lobular & 19 & 11.7 \\
lobular+tubular & 1 & 0.6 \\
medular & 2 & 1.2 \\
mucinous & 1 & 0.6 \\
papilar & 4 & 2.5 \\
solid CNC & 1 & 0.6 \\
tubular & 2 & 1.2 \\
tubular-lobular & 2 & 1.2 \\
Total & 163 & 100.0 \\
\hline
\end{tabular}

tive SLN without ALND were excluded. Majority of patients underwent pre-operative ultrasound guided large-needle core biopsy for breast cancer diagnosis (typing). Nonpalpable breast lesion were localized by hook wire under ultrasound or stereotactic guidance. The surgical tumor samples were examined by hematoxilin/eosin stained serial sectioning for tumor typing and surgical margins status. Immunohistochemistry was used for histologic evaluation of hormonal receptors, HER2 and Ki67 receptors. The tumors with unclear HER2 status in immunohistochemistry $(2+)$ were additionally examined by fluorescence in situ hybridization (FISH) method for definitive diagnosis.

Lymphatic mapping was done with blue dye (PATENT BLUE V ${ }^{\circledR}$, Guerbet, France) according to the roules of Guiliano et al. [2]. Histologic examination for metastases in SLN and non-SLN was provided by frozen section during the breast surgery and later by hematoxilin/eosin stained serial sectioning and cytokeratin imunohistochemistry [8]. Following clinical and pathological characteristics were analyzed to predict the likelihood of non-SLN metastases: age of the patients, staging of the disease, histologic type and grading of the tumors, estrogen and progesteron receptor status, HER-2 receptor status and $\mathrm{Ki}-67$ protein, angioinvasion of the tumor, metastases in SLN and non-SLN. Relative frequencies of individual characteristics between sample groups were statistically tested by Chi-square test at significance level $p=0.5$, when sample sizes in groups were small $(\leq 5)$ by Fisher's exact test.

\section{Results}

We analyzed clinical and pathologic data from 163 patients who underwent surgical treatment of breast cancer with SLNB followed by ALND at the $2^{\text {nd }}$ Department of OB/ GYN, University Hospital of Bratislava, Slovakia between $2001-2013$. The average age of patients was 56,31 years. Most of the tumors were ductal infiltrating carcinoma, the tumor typing distribution in the study group of patients is shown in Tab. 1 . The average tumor size was $16,91 \mathrm{~mm}$, i.e. majority of patients were in pT1c stadium of the disease (Fig. 1). 72,4\% of the patients had an estrogen positive tumor, $70,6 \%$ of the patients were also positive in the progesteron receptors of the tumors. HER2 receptors were positive in $35,6 \%$ of patients, Ki67 protein in $50,3 \%$ of the patients. In terms of molecular classification, there were $10,4 \%$ patients with triple negative tumors (Tab. 2).

Metastasis in SLN were present in 67 (41\%) of patients, 48 patients $(29,4 \%)$ had also metastasis in non-SLN. Thus, in

Table 2. Prognostic and predictive factors

\begin{tabular}{lccccc}
\hline Percent \% & ER & PR & HER-2 & Ki 67 & angioinvasion \\
\hline Positive & 72.4 & 70.6 & 35.6 & 50.3 & 27 \\
Negative & 26.4 & 28.2 & 52.8 & 46.0 & 73 \\
\hline
\end{tabular}




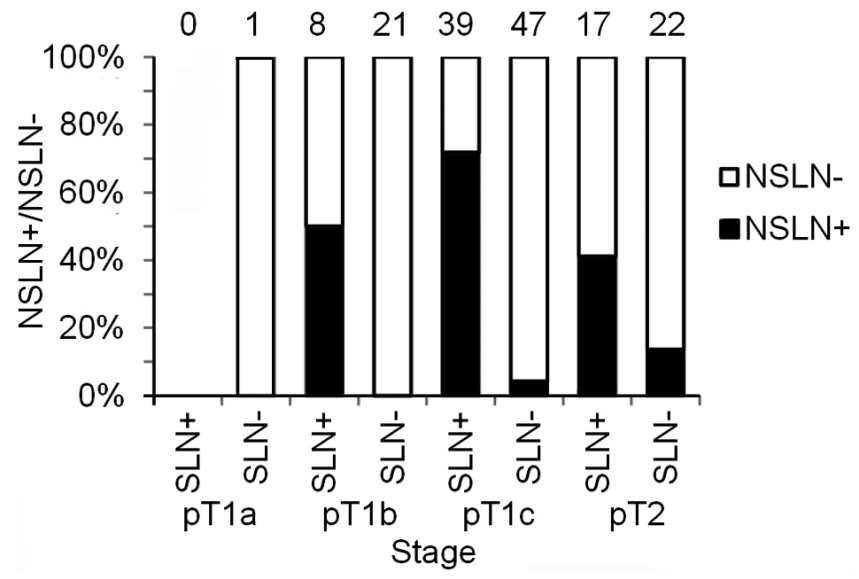

Figure 2. The ratio between non-SLN positive (NSLN+) and non-SLN negative lymph nodes (NSLN-) in patients with positive SLN increases with the stage of the disease. The difference between values for the pT1c and pT2 stadium was statistically significant $(p=0.0296)$. The numbers of patients in groups are listed above the columns.

$61,2 \%$ of patients metastases were present in SLN and nonSLN as well. The ratio between non-SLN positive / non-SLN negative lymph nodes in patients with positive SLN increases with the stage of the disease, the difference between values for the pT1c and pT2 stadium was statistically significant (p $=0.0296)$ (Fig. 2). The same applies to grading (Tab. 3) for this group of patients: The ratio between non-SLN positive I non-SLN negative lymph nodes rises with the grade of the tumors, but the differences were insignificant $(p>0.05)$ (Fig. 3). We could not find significant differences between the groups with and without angioinvasion of the tumor. The ratio between non-SLN positive and non-SLN negative lymph nodes did not rise significantly with the presence of tumor emboli or tumor masses within blood and/or lymphatic vessels $(p>0.05)$, probably for small number of patients with angioinvasion (Fig. 4). Patients were divided into roughly equal-size groups. Specially selected group was then made, consisting of patients older than 70 years. This group was characterized by the absence SLN negative / nonSLN positive combination, and a majority of patients (79\%) were SLN as well as non-SLN negative (Fig. 5). Frequency distributions of combinations of positivity / negativity of SLN and non-SLN in patients in groups divided by tumor markers is shown in Fig. 6.

Table 3. Tumor grading

\begin{tabular}{ccc}
\hline Grading & Frequency & Percent \\
\hline 1 & 27 & 16.6 \\
2 & 74 & 45.4 \\
3 & 62 & 38.0 \\
Total & 163 & 100.0 \\
\hline
\end{tabular}

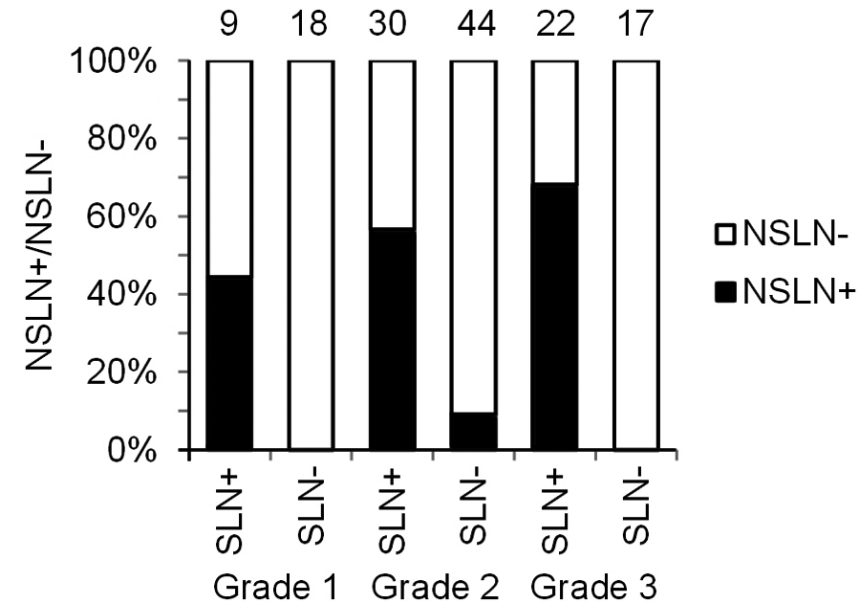

Figure 3. The ratio between non-SLN positive (NSLN+) and non-SLN negative lymph nodes (NSLN-) in patients with positive SLN rises with the grade of the tumors, but the differences were insignificant $(p>0.05)$. The numbers of patients in groups are listed above the columns.

\section{Discussion}

The dilemma whether all of the patients with positive SLN need an ALND continues. Axillary nodal status in breast cancer is one of the most important prognostic factors for both breast cancer recurrence and patient survival [1]. Since the 1990s, SLNB has become the standard staging procedure for patients with invasive breast cancer [8-11]. Since the procedure was introduced, high number of studies on SLN biopsy in breast cancer have been published in the world medical literature. Today, there is enough data-based evidence showing that SLNB can accurately stage the axilla in early breast cancer with clinically node-negative disease $[10,11]$. Patients with

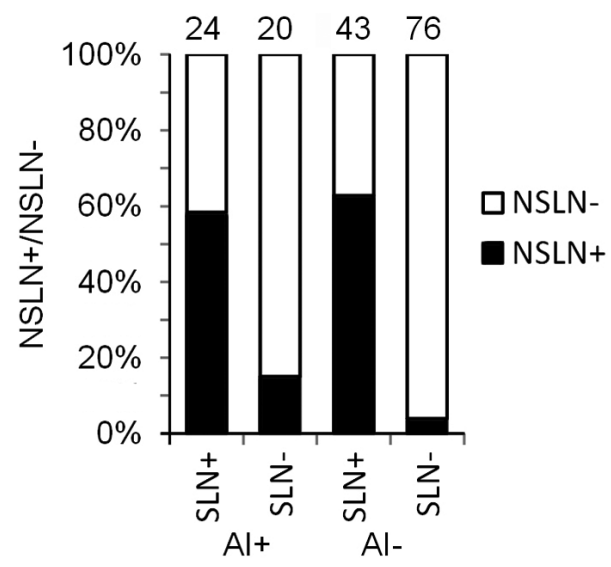

Figure 4. The ratio between non-SLN positive and non-SLN negative lymph nodes did not rise significantly with the presence of angioinvasion $(\mathrm{AI})(\mathrm{p}>0.05)$. The numbers of patients in groups are listed above the columns. 


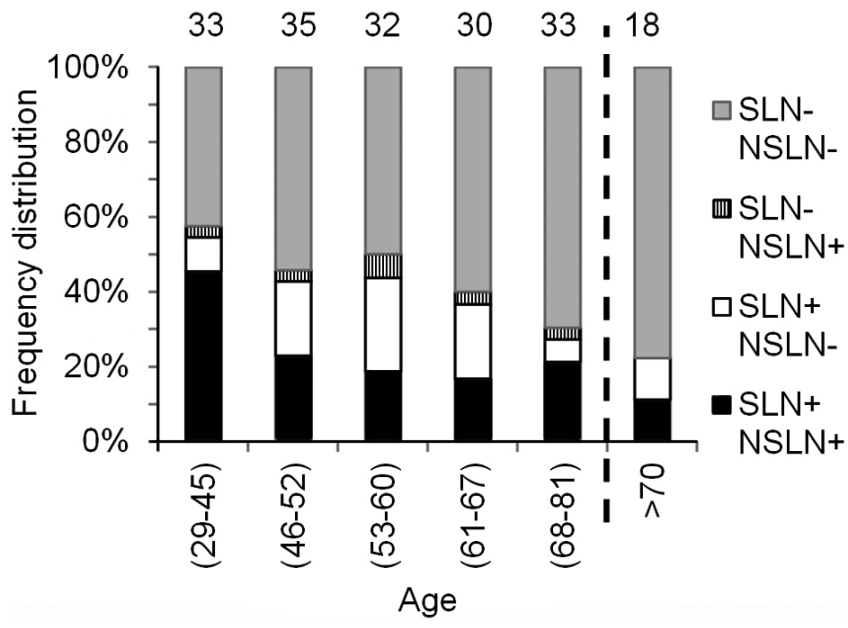

Figure 5. Frequency distributions of combinations of positivity/negativity of SLN and non-SLN in patients divided by age. The numbers of patients in groups are listed above the columns.

histologically negative SLN can avoid aggressive ALND and, therefore have lower postoperative morbidity [6, 7].

NSABP B-32, the largest surgical prospective randomized phase III trial was designed to compare overall survival (OS), disease-free survival (DFS), and morbidity between SLNB alone to conventional ALND in clinically node-negative breast cancer patients [10]. 10-yr follow-up results of NSABP B-32 were published recently [11]. The authors present 10 year outcome data for primary endpoints as well as updated data on the effect of occult metastases, found later in the SLN by central, detailed pathologic analysis. At 10 years, there continues to be no significant difference in OS $(87.8 \%$ for SLNB alone and $88.9 \%$ for SLNB+ALND) or in DFS (76.9\% for both groups). The cumulative incidences of local-regional events were low and not significant. The cumulative incidences of local-regional events were low (4.0\% vs. $4.3 \%)$ and not significant $(\mathrm{p}=0.77)[11]$.

The examination of the clinically negative SLN by the pathologist through frozen section histologic procedure during the breast surgery allows perfoming the ALND as one step procedure in the cases of positive $\operatorname{SLN}[8,9]$. The additional evaluation of SLN by serial sectioning and cytokeratin immunohistochemistry can bring postoperative positive results in histological examination [12-14] (Fig. 7, Fig. 8). But not all of the patients with histologically positive SLN have also positive non-SLN. The ALND is an overtreatment for this subgroup of patients, who are also exposed to the postoperative risks of the arm morbidity. The likelihood of non-SLN metastases depends on several factors but none of these could by now alone identify a subgroup of patients in whom ALND could be avoided.

Many working groups developed nomograms to predict non-SLN status in breast cancer patients [15-22]. We had also used on of them, the Memorial Sloan-Kettering Cancer Center

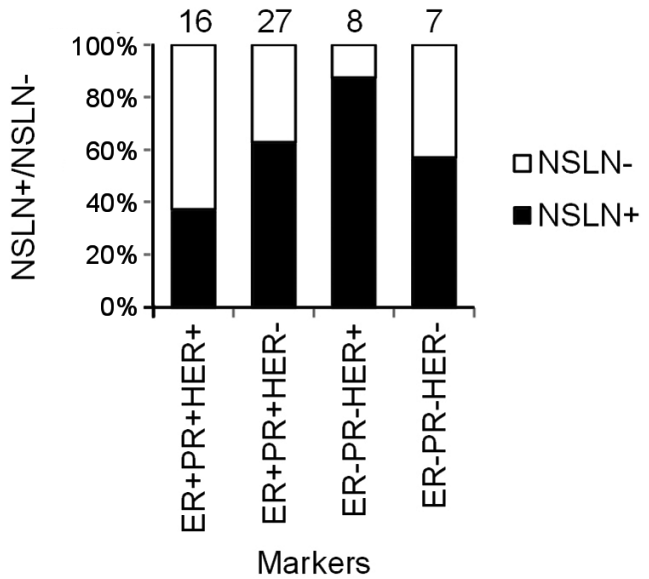

Figure 6. The ratio between non-SLN positive (NSLN+) and non-SLN negative lymph nodes (NSLN-) in patients with positive SLN, divided by the presence/absence of tumor markers. The numbers of patients in groups are listed above the columns.

(MSKCC) nomogram in the past for the same purpose (http:// nomograms.mskcc.org/breast/). This nomogram calculates the probability of the involment of additional axillary lymph nodes in the cases of positive sentinel nodes, based on 9 tumor characteristics. It has been later evaluated in prospective trials and there was no general agreement about its accuracy. However, recently $\mathrm{Bi}$ et al. [22] could in their validation study on 1,576 patients show, that the MSKCC nomogram can provide an accurate prediction of the probability of non-SLN metastasis, and offers a reference basis about axillary lymph node dissection. Another efforts [18-21] to develop nomograms in order to predict which patients should undergo an ALND, fail to identify patients who really benefit from this procedure.

The axillary recurrence rate occured after an ALND in patients with a positive SLNB is low. Recent publications show rates that vary between 0.2 and $0.9 \%$ for micrometastatic disease of SLN and around 1.0\% in case of macrometastatic disease [23]. Recently, several studies (IBCSG 23-01, ACOSOG Z0011, EORTC AMAROS) in patients with positive SLNB who predominantly underwent breast-saving therapy have reported low axillary recurrence rate when ALND had not been performed [24-26, 29].

A prospective randomized trial (ACOSOG Z0011) tried to investigate whether ALND could be safely omitted in these patients [24]. This was the only prospective trial in which patients with sentinel node metastases were randomized to undergo ALND after SLNB versus SLNB without specific axillary treatment. All these patients were treated with breast conserving therapy and tangential field whole breast irradiation. In addition, the majority of the patients (97\%) in that study received adjuvant systemic treatment. At a median follow-up of 6.3 years, no significant difference was seen in the axillary recurrence rates between the two groups $(0.5 \%$ in the ALND group vs. $0.9 \%$ in the group without ALND). Overall 


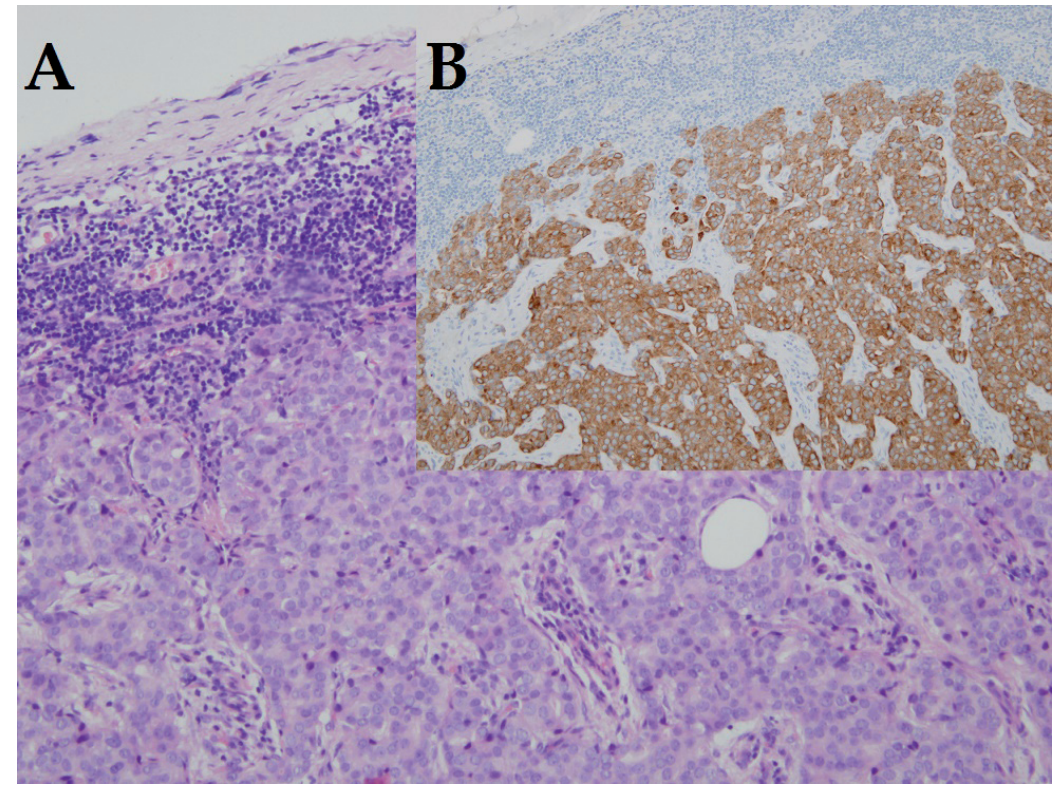

Figure 7. Positive sentinel lymph node on metastases of invasive ductal carcinoma of the breast. H\&E, x100 (A) and cytokeratin immunohistochemistry CKAE1/3, x100 (B).

survival was not different in both study arms [24]. These data suggest that it is reasonable and safe not to perform ALND in the presence of 2 macrometastatic sentinel nodes in patients scheduled for breast-conserving surgery (not mastectomy), provided they receive whole breast irradiation and systemic adjuvant treatment. Unfortunately, the trial ended early because accrual was slow and the axillary recurrence rates were lower than expected in both arms. The slow accrual probably implies that in daily practice there is still concern about the safety of omitting an ALND. In 2012 Francissen et al [23] published a literature research performed in the PubMed database to this topic. A total of 216 articles were found in the PubMed database, but after responsible assessment only 30 articles were eligible for the analysis. This review shows that the axillary recurrence rate is low in patients with positive SLN, even if an ALND is not performed. In studies that included

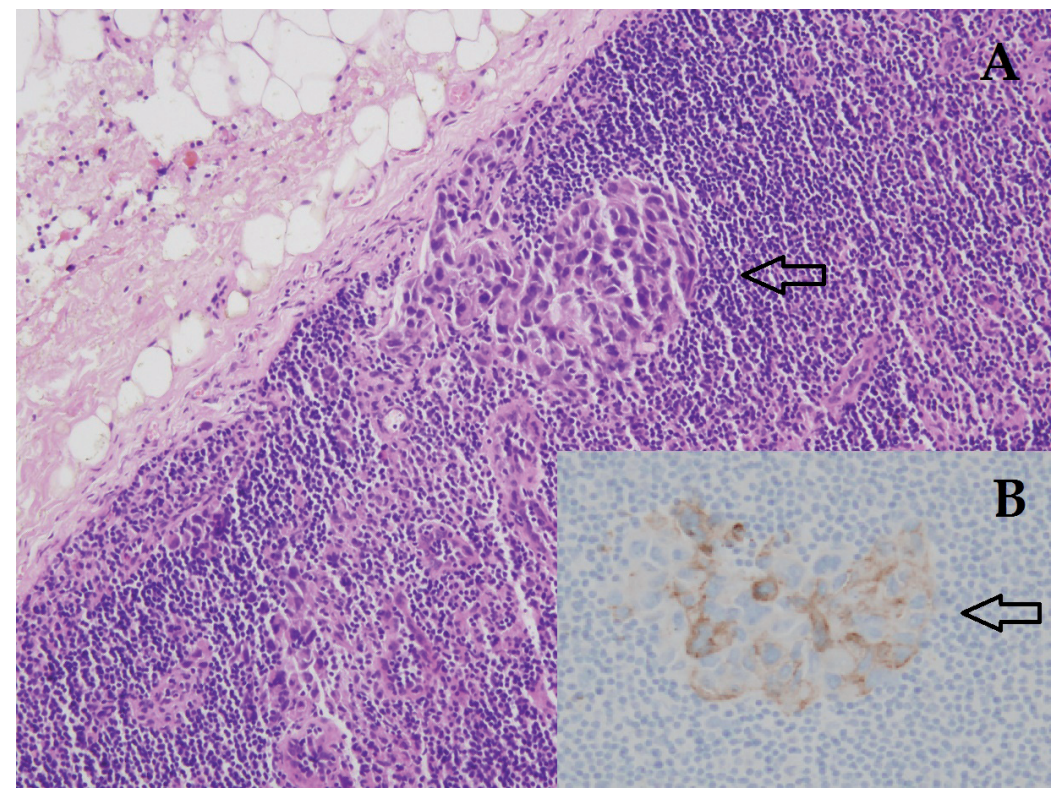

Figure 8. Micrometastases of breast carcinoma in sentinel lymph node (arrows). H\&E, x100 (A) and CKAE1/3, x200 (B). 
at least 100 patients who did not undergo an ALND although they had a tumor-positive SLN, the axillary recurrence rates varied between 0 and $0.9 \%$ for micrometastatic disease and 0,2 to $1,2 \%$ for macrometastatic disease. These rates are comparable to those seen in patients with a positive SLNB in which an ALND had been performed (axillary recurrence rates between 0.2 and 1.0\%) [23]. Moreover, in the current guidelines adjuvant systemic therapy is advised on the basis of tumor and patient characteristics and axillary lymph node involvement [27]. Treatment recommendations are rarely altered by the additional information gained by the results from ALND nodes, although patients with four or more positive lymph nodes are supposed to receive adjuvant radiotherapy on the axilla and supraclavicular region. Not only systemic therapy but also adjuvant radiotherapy can be regarded as a treatment modality for any remaining axillary lymph node metastases $[29,30]$. Radiotherapy as a routine part od breast conserving therapy includes also the lowest portion of the axilla. Van Welly et al [30] published systematic review demonstrated that patients with a negative SLN who underwent radiotherapy had a significantly lower rate of axillary recurrences as compared to patients who had not been not treated with postoperative radiotherapy of the breast.

Van Deurzen et al. [31] reviewed consecutive series of 317 patients with invasive breast cancer and a tumorpositive SLN, followed by an ALND. Microanatomic SLN tumor features (subcapsular, combined subcapsular and parenchymal, parenchymal, extensive localization, multifocality, and the penetrative depth from the SLN capsule) predicted non-SLN involvement. However, based on these features no subgroup of patients could be selected with less than $10 \%$ non-SLN involvement. Similarly Fink et al. [20] reevaluated positive SLN from 236 patients with SLNB followed by ALND according to the microanatomic location of SLN metastases. Based on so called S classification of SLN they could predict the likelihood of non-SLN metastases. S classification describes the centripetal penetration depth of metastases into the SLN. The authors evaluated also the microanatomic location of metastases: subcapsular, parenchymal, combined, multifocal, and extensive. This characteristics were compared with the standard histological classification of micro/macrometastases. They found that $S$ classification was a statistically significant predictor of non-SLN status and patient outcome [20]. Nodal ratio and size of the SLN metastases as a continuous variable to help guide decision-making for ALND is the main principle of the M.D. Anderson nomogram developed, after the ACOSOG Z0011trial was terminated (http://www3.mdanderson.org/ app/medcalc/bc_nomogram). Recently, Caretta-Weyer et al. [26] re-analyzed the ACOSOG Z0011 trial and concluded that overall 2,637 patients $(4.4 \%(2,637 / 59,431)$ of the total cohort but $38 \%(2,637 / 6,942)$ of patients with SLN mapping and positive nodes) met inclusion criteria for ACOSOG Z0011, had 1 or 2 positive lymph nodes, and could have been spared an ALND. Of these 2,637 patients, $46 \%$ received complete ALND and 54\% received only SLN biopsy. Widespread implementa- tion of ACOSOG Z0011 trial results could potentially spare $38 \%$ of older breast cancer patients who undergo SLN mapping with positive lymph nodes an ALND [26].

Women over 60 years of age with a screen-detected breast cancer in general have $\mathrm{a}<10 \%$ risk of axillary lymph node involvement [26].This is in agreement with results in the present study (Fig. 4). Favourable prognostic factors (small low-grade hormone receptor positive tumor, age over 65 , and eventually low risk multigene assays) and negative preoperative clinical status of the axilla (assesed by palpation and sonography) is linked to little to none benefit from axillary staging. It seems, that it may be more beneficial to these patients to abstain from axillary dissection. Further definitions will be given by German study INSEMA, which started recently and basically will aim to avoid axillary staging in most patients [32].

Today, ALND is mainly a diagnostic procedure and improves clinical outcome only in patients with lymph node metastases. Removal of tumor-free lymph nodes increases morbidity and has no prognostic impact. When axillary lymph node metastases are documented by fine-needle aspiration cytology or large-needle core biopsy of a clinically suspicious node under ultrasound guidance before surgery, the current consensus is that a complete level I and II axillary dissection should be performed [33]. Neoadjuvant chemotherapy has been shown to sterilize involved axillary lymph nodes in a considerable proportion (approximately 30-40\%) of patients [28]. Several studies have demonstrated that SLNB is feasible and accurate in this setting. Thus, for patients with documented positive axillary nodes or for those with a high likelihood of axillary nodal involvement (clinically palpable nodes), preoperative chemotherapy and SLNB could potentially spare the patient ALND. In such cases SLNB should be performed after the neoadjuvant treatment because in around $30 \%$ of cases the axilla becomes negative. If one or more sentinel nodes are involved after neoadjuvant treatment or a mastectomy is planned, ALND still has to be performed [28, 34].

Axillary staging is a diagnostic procedure determining adjuvant treatment decisions. For many patients (luminal A, HER 2-positive, triple-negative tumors) the systemic treatment is already predefined by tumor biology. In these patients the axillary status is only significant in the planning of regional therapy. In case of positive SLNB before preoperative chemotherapy, ALND may be omitted under certain conditions (tumor $<5 \mathrm{~cm}, \mathrm{cN} 0$, less than 3 lymph nodes affected, no extracapsular spread, planned whole breast irradiation for brest conserving therapy, planned adequate systemic treatment, following informed consent) [24, 32, 34].

\section{Conclusions}

Large, prospective randomized studies concerning patients with a potentially higher risk for regional recurrences such as multiple macrometastases in the SLN, patients with larger primary tumors, patients who underwent neoadjuvant chemotherapy or patients undergoing mastectomy or 
breast conserving therapy without radiotherapy are needed [34]. Future research will need to better define the role of complete ALND for subgroups of patients for whom the risk of axillary recurrence is low, particularly those patients with low volume axillary disease treated with mastectomy [24, 34]. A new SOUND trial (Sentinel node vs Observation after axillary UltraSouND) is ongoing at the European Institute of Oncology in Milan, Italy [35]. The aims of this prospective randomized study are to verify whether, in presence of a negative preoperative axillary assessment, SLN can be spared in patient in clinically T1 N0 stadium with negative axillary ultrasound finding (and negative FNAC in presence of doubtful findings), and to verify if the decision on adjuvant medical treatment can be taken according only to the biology of the tumour without the prognostic information achieved by SLNB on the nodal status. The primary endpoint of the study is distant-disease free survival. Secondary endpoints will be the cumulative incidence of distant recurrences, the cumulative incidence of axillary recurrences, the disease free survival and the overall survival. Other secondary endpoints are quality of life and evaluation of type of adjuvant treatment administered. Similarly, the already above mentioned German INSEMA trial, in which cN0/iN0 patients are randomized to no surgical treatment to the axilla vs. SLNB, has already started [32]. Results of those prospective trials could bring a new view into the breast surgery, especially for those patients, where any axillary surgical staging could be avoided.

\section{References}

[1] CARTER CL, ALLEN C, HENSON DE. Relation of tumor size, lymph node status, and survival in 24,740 breast cancer cases. Cancer 1989, 63: 181-187. http://dx.doi.org/10.1002/1097-0142(19890101)63:1<181::AID-CNCR2820630129>3.0.CO;2-H

[2] GIULIANO AE, KIRGAN DM, GUENTHER JM, MORTON DL. Lymphatic mapping and sentinel lymphadenectomy for breast cancer. Ann Surg 1994, 220: 391-401. http://dx.doi. org/10.1097/00000658-199409000-00015

[3] KRAG D, WEAVER D, ASHIKAGA T, MOFFAT F, KLIMBERG VS et al. The sentinel node in breast cancer-a multicenter validation study. N Engl J Med 1998; 339: 941-946. http://dx.doi. org/10.1056/NEJM199810013391401

[4] VERONESI U, VIALE G, PAGANELLI G, ZURRIDA S, LUINI A et al. Sentinel lymph node biopsy in breast cancer: ten-year results of a randomized controlled study. Ann Surg 2010; 251: 595-600. http://dx.doi.org/10.1097/SLA.0b013e3181c0e92a

[5] BORGSTEIN PJ, MEYER S, PIJPERS RJ. Functional lymphatic anatomy for sentinel node biopsy in breast cancer: echoes from the past and the periareolar blue method. Ann Surg 2000; 232: 81-9. http://dx.doi.org/10.1097/00000658-200007000$\underline{00012}$

[6] RIETMAN JS, GEERTZEN JH, HOEKSTRA HJ, BAAS P, DOLSMA VW et al. Long term treatment related upper limb morbidity and quality of life after sentinel lymph node biopsy for stage I or II breast cancer. Eur J Surg Oncol 2006; 32: 148-52. http://dx.doi.org/10.1016/j.ejso.2005.11.008
[7] FLEISSIG A, FALLOWFIELD LJ, LANGRIDGE CI, JOHNSON L, NEWCOMBE RG et al. Post-operative arm morbidity and quality of life. Results of the ALMANAC randomised trial comparing sentinel node biopsy with standard axillary treatment in the management of patients with early breast cancer. Breast Cancer Res Treat 2006; 95: 279-93. http:// dx.doi.org/10.1007/s10549-005-9025-7

[8] LYMAN GH, GIULIANO AE, SOMERFIELD MR, BENSON $\mathrm{AB}, \mathrm{BODURKA}$ DC et al. American society of clinical oncology guideline recommendations for sentinel lymph node biopsy in early-stage breast cancer. J Clin Oncol 2005; 23: 7703-7720. http://dx.doi.org/10.1200/JCO.2005.08.001

[9] KUERER HM, NEWMAN LA. Lymphatic mapping and sentinel lymph node biopsy for breast cancer: Developments and resolving controversies. J Clin Oncol, 2005, 23: 1698-1705 http://dx.doi.org/10.1200/JCO.2005.09.047

[10] KRAG DN, ANDERSON SJ, JULIAN TB, BROWN AM, HARLOW SP et al. Sentinel-lymph-node resection compared with conventional axillary-lymph-node dissection in clinically node-negative patients with breast cancer: overall survival findings from the NSABP B-32 randomised phase 3 trial. Lancet Oncol 2010; 11: 927-933. http://dx.doi.org/10.1016/ $\underline{\text { S1470-2045(10)70207-2 }}$

[11] JULIAN TB, ANDERSON SJ, KRAG DN, HARLOW SP, CONSTANTINO JP et al. 10-yr follow-up results of NSABP $\mathrm{B}-32$, a randomized phase III clinical trial to compare sentinel node resection (SNR) to conventional axillary dissection (AD) in clinically node-negative breast cancer patients J Clin Oncol 2013, 31: (suppl; abstr 1000).

[12] VIALE G, MAIORANO E, MAZZAROL G, ZURRIDA $S$, GALIMBERTI V et al. Histologic detection and clinical implications of micrometastases in axillary sentinel lymph nodes for patients with breast carcinoma. Cancer 2001, 92: 1378-1384. http://dx.doi.org/10.1002/1097-0142(20010915)92:6<1378::AID-CNCR1460>3.0.CO;2-Y

[13] CSERNI G, BIANCHI S, BOECKER W, DECKER T, LACERDA $M$ et al. Improving the reproducibility of diagnosing micrometastases and isolated tumor cells. Cancer 2005; 103: 358-67 http://dx.doi.org/10.1002/cncr.20760

[14] CSERNI G, GREGORI D, MERLETTI F, SAPINO A, MANO $\mathrm{MP}$ et al. Meta-analysis of nonsentinel node metastases associated with micrometastatic sentinel nodes in breast cancer. $\mathrm{Br}$ J Surg 2004; 91: 1245-52. http://dx.doi.org/10.1002/bjs.4725

[15] BARRANGER E, COUTANT CH, FLAHAULT A, DELPECH Y, DARAI E et al. An axilla scoring system to predict non-sentinel lymph node status in breast cancer patients with sentinel lymph node involvement. Breast Cancer Res Treat, 2005; 91: 113-119. http://dx.doi.org/10.1007/s10549-004-5781-z

[16] VIALE G, MAIORANO E, PRUNERI G, MASTROPASQUA MG, VALENTINI S et al. Predicting the risk for additional axillary metastases in patients with breast carcinoma and positive sentinel lymph node biopsy. Ann Surg 2005; 241: 319-25 http://dx.doi.org/10.1097/01.sla.0000150255.30665.52

[17] FLEMING FJ, KAVANAGH D, CROTTY TB, QUINN CM, MCDERMOTT EW et al. Factors affecting metastases to nonsentinel lymph nodes in breast cancer. J Clin Pathol 2004, 57: 73-76. http://dx.doi.org/10.1136/jcp.57.1.73 
[18] VAN ZEE KJ, MANASEH DM, BEVILACQUA JL, BOOLBOL SK, FEY JV et al. A nomogram for predicting the likelihood of additional nodal metastases in breast cancer patients with a positive sentinel node biopsy. Ann Surg Oncol 2003; 10: 1140-51. http://dx.doi.org/10.1245/ASO.2003.03.015

[19] COUTANT CH, ROUZIER R, FONDRINIER E, MARCHALL F, GUILEMMIN F et al. Validation of the Tenon breast cancer score for predicting non-sentinel lymph node status in breast cancer patients with sentinel lymph node metastasis: a prospective multicenter study. Breast Cancer Res Treat 2009, 113: 537-543 http://dx.doi.org/10.1007/s10549$\underline{008-9967-7}$

[20] FINK AM,WONDRATSCH H, LASS H, JANAUER M, SEVELDA $P$ et al. Validation of the $S$ classification of sentinel lymph node and microanatomic location of sentinel lymph node metastases to predict additional lymph node involvement and overall survival in breast cancer patients. Ann Surg Oncol 2011, 18: 1691-1697. http://dx.doi.org/10.1245/ $\underline{\text { s10434-010-1545-7 }}$

[21] PAL E, PROVENZANO E, DUFFY SW, PINDER SE, PURUSHOTAM AD. A model for predicting non-sentinel lymph node metastatic disease when the sentinel lymph node is positive. Br J Surg 2008, 95: 302-309. http://dx.doi.org/10.1002/ bjs. 5943

[22] BI X, WANG Y, LI M, CHEN P, ZHOU Z et al. Validation of the Memorial Sloan Kettering Cancer Center nomogram for predicting non-sentinel lymph node metastasis in sentinel lymph node-positive breast-cancer patients. Onco Targets Ther, 2015, 8: 487-493

[23] FRANCISSEN CMTP, DINGS PJM, VAN DALEN T, STROBBE LJA, VAN LAARHOVEN HWM et al. Axillary recurrence after a tumor-positive sentinel lymph node biopsy without axillary treatment: a review of the literature. Ann Surg Oncol 2012, 19: 4140-4149. http://dx.doi.org/10.1245/s10434-012-2490-4

[24] GULIANO AE, HUNT KK, BALLMAN KV, BEITSCH PD,WHITWORTH PW et al. Axillary dissection vs no axillary dissection in women with invasive breast cancer and sentinel node metastasis. A randomized clinical trial. JAMA 2011; 305: 569-575. http://dx.doi.org/10.1001/jama.2011.90

[25] BOUGHEY JC, SUMAN VJ, MITTENDORF EA, AHRENDT GM, WILKE LG et al. Sentinel lymph node surgery after neoadjuvant chemotherapy in patients with node-positive breast cancer: the ACOSOG Z1071 (Alliance) clinical trial. JAMA 2013; 310: 1455-1461. http://dx.doi.org/10.1001/ jama.2013.278932

[26] CARETTA-WEYER H, GREENBERG CG, WILKE LG, WEISS J, LOCONTE NK et al. Impact of the American College of Surgeons Oncology Group (ACOSOG) Z0011 trial on clinical management of the axilla in older breast cancer patients: a SEER-Medicare analysis. Ann Surg Oncol 2013; 20: 4145-52. http://dx.doi.org/10.1245/s10434-013-3193-1

[27] HANF V, SCHUTZ F, LIEDTKE C, THILL M on behalf of the AGO Breast Committee: AGO recommendations for the diagnosis and treatment of patients with early breast cancer: Update 2015. Breast Care 2015; 10: 189-197 http://dx.doi. org/10.1159/000431346

[28] KUEHN T, BAUERFEIND I, FEHM T, FLEIGE B, HAUSSCHILD M et al. Sentinel lymph-node biopsy in patients with breast cancer before and after neoadjuvant chemotherapy (SENTINA): a prospective, multicentre cohort study. Lancet Oncol 2013; 14: 609-618 http://dx.doi.org/10.1016/S14702045(13)70166-9

[29] DONKER M, VAN TIENHOVEN G, STRAVER M, MEIJNEN P, VAN DE VELDE CJH et al. Radiotherapy or surgery of the axilla after a positive sentinel node in breast cancer (EORTC 10981-22023 AMAROS): a randomised, multicentre, open-label, phase 3 non-inferiority trial. Lancet Oncol 2014,15: 1303-1310. http://dx.doi.org/10.1016/S1470-2045(14)70460-7

[30] VAN WELLY BJ, TEERENSTRA S, SCHINAGL DA, AUFENACKER TJ, DE WILT JH et al. Systematic review of the effect of external beam radiation therapy to the breast on axillary recurrence after negative sentinel lymph node biopsy. $\mathrm{Br}$ J Surg. 2011; 98: 326-33. http://dx.doi.org/10.1002/bjs.7360

[31] VAN DEURZEN CH, VAN HILLEGERSBERG R, HOBBELINK MG, SELDENRIJK CA, KOELEMIJ R et al. Predictive value of tumor load in breast cancer sentinel lymph nodes for second echelon lymph node metastases. Cell Oncol. 2007; 29: 497-505

[32] REIMER T, HARTMANN S, STACHS A, GERBER B. Local treatment of the axilla in early breast cancer: concepts from the national surgical adjuvant breast and bowel project B-04 to the planned Intergroup Sentinel Mamma Trial. Breast Care 2014; 9: 87-95. http://dx.doi.org/10.1159/000360411

[33] GARCIA-ORTEGA MJ, BENITO MA, VAHAMONDE EF, TORRES PR, VELASCO AB et al. Pretreatment axillary ultrasonography and core biopsy in patients with suspected breast cancer: Diagnostic accuracy and impact on management. Eur J Radiol 2011, 79: 64-72. http://dx.doi.org/10.1016/j. ejrad.2009.12.011

[34] FITZAL F, GALIMBERTI V, KUEHN T, RUTGERS RJ, UNTCH M Lymph node staging in invasive breast cancer. Breast Care 2014; 9: 211-214. http://dx.doi.org/10.1159/000365315

[35] GENTILINI O, VERONESI U Abandoning sentinel lymph node biopsy in early breast cancer? A new trial in progress at the European Institute of Oncology of Milan (SOUND: Sentinel node vs Observation after axillary UltraSouND). Breast 2012; 21: 678-81 http://dx.doi.org/10.1016/j.breast.2012.06.013 